\title{
ELABORAÇÃO, ANÁLISE QUÍMICA E SENSORIAL DESCRITIVA DE ACEITAÇÃ̃O DE BISCOITOS TIPO COOKIES DE SOJA E QUINOA COM E SEM GLÚTEN
}

\author{
Glaciela Cristina Rodrigues da Silva Scherer ${ }^{1}$, Janine Martinazzo ${ }^{1}$, Fernanda Hart Weber ${ }^{2}$ e \\ Nádia Ligianara Dewes Nyari ${ }^{3}$ \\ ${ }^{1}$ Universidade Regional Integrada do Alto Uruguai e Missões - URI- Erechim, Departamento \\ de Engenharia de Alimentos, Mestre em Engenharia de Alimentos \\ ${ }^{2}$ Universidade Estadual do Rio Grande do Sul, Departamento de ciências agrárias, Doutora \\ em Ciência e Tecnologia de Alimentos \\ ${ }^{3}$ Faculdade LaSalle de Lucas do Rio Verde - MT, Doutora em Engenharia de alimentos \\ E-mail para contato: nadialigianara@hotmail.com
}

\begin{abstract}
RESUMO - Este estudo teve como objetivo desenvolver biscoitos tipo cookies com e sem glúten enriquecidos com soja e quinoa. Biscoitos ou cookies sem glúten que geralmente possuem teor reduzido de proteínas, para isso utilizou-se a soja e quinoa que podem aumentar o valor nutricional desses produtos. Os cookies foram elaborados e submetidos as análises físico-químicas de proteínas, lipídios, carboidratos, sódio e valor calórico. A avaliação sensorial dos produtos foi realizada pela Análise Descritiva Quantitativa (ADQ). Os teores de proteína para os dois tipos de cookies foram maiores aos verificados para a amostra comercial deste tipo de produto. Os resultados de ADQ demonstraram que o cookie sem glúten foi considerado com sabor moderado, mas ainda superior (mais doce) do que o cookie sem glúten. Em relação à aceitabilidade, os cookies obtiveram médias ligeiramente superiores a "gostei moderadamente" na escala utilizada e não diferiram estatisticamente $(\mathrm{p}<0,05)$ para todos os atributos avaliados, exceto para o sabor.
\end{abstract}

Palavras-chave: Cookies. Glúten. Análise Sensorial.

DOI: $10.5965 / 24473650412018066$

\section{INTRODUÇÃO}

O biscoito é o produto obtido pela mistura de farinhas, féculas ou amidos com outros ingredientes, submetidos a amassamento e cocção, fermentados ou não (BRASIL, 2005). O Brasil tem importante posição como exportador de biscoitos, sendo que os principais mercados, em 2017, foram Angola, Venezuela, Cuba, Argentina, Estados Unidos (EUA), Uruguai, Paraguai, Perú, Chile e Japão (ABIMAPI, 2018).

Nos EUA, os biscoitos são denominados "cookies" e são definidos como produtos assados à base de cereais que possuem altos níveis de açúcar e de gordura e baixos níveis de água (1-5\%) (MORAES, 2010). Os biscoitos tipo cookies tem sido formulados com a intenção de implementar a fortificação nutricional de alimentos com fibras e/ou proteínas, atender consumidores que necessitam dietas com aumento ou restrição de determinado ingrediente e pela facilidade tecnológica de incorporar diferentes ingredientes funcionais à 
formulação sem perda de características físicas e sensoriais (MARETI et al., 2010; CORTAT et al., 2015; GOES et al., 2017; OLIVEIRA et al., 2017; RIGO et al., 2017; SABINO et al., 2017; MAKINO et al., 2018).

Neste sentido, verifica-se um número cada vez maior de pesquisas desenvolvidas para elaboração de cookies que contenham ingredientes funcionais, resultando em alimentos de elevado teor nutricional e qualidade tecnológica, alimentos estes que são de extrema importância para fortificar a alimentação da população em geral (SILVA et al., 1998; CORTAT et al., 2015; dos SANTOS et al., 2015; VIEIRA et al., 2015; FIORAVANTE et al., 2016; PEREIRA, 2016; da SILVA et al., 2017).

Mareti et al. (2010) formularam biscoitos com propriedades hipocolesterolêmicas pela combinação de farinha desengordurada de soja e farelo de aveia em substituição parcial à farinha de trigo. Tanto a soja como a quinoa possuem a vantagem da ausência do glúten apresentando uma alternativa na elaboração de produtos alimentares para as pessoas celíacas, que são as alérgicas ao glúten, pois o tratamento da doença celíaca é fundamentalmente dietético e consiste na exclusão do glúten, que está presente no trigo, centeio, cevada, aveia e em seus derivados (ARAÚJO et al., 2010; LOPES, 2017).

O consumo de soja como alimento pela população tem aumentado devido aos benefícios para a saúde, pois é fonte proteica de alta qualidade, além de fornecer compostos bioativos, como as isoflavonas, entre outros (CARRÃO-PANIZZI; SILVA, 2011). A farinha obtida da soja é um produto versátil devido a sua funcionalidade, qualidade nutricional e baixo custo (DEVI; HARIPRIYA, 2014). A quinoa é altamente importante na dieta humana porque é isenta de glúten, podendo ser consumida por pessoas com doença celíaca, além de possuir alto valor nutricional, contendo fibras, minerais, vitaminas e aminoácidos, bem como compostos bioativos benéficos para a saúde, como os polifenóis (GEWEHR et al., 2012; NAVRUZVARLI; SANLIER, 2016; TEKGÜLER et al., 2016; VILCACUNDO; HERNÁNDEZLEDESMA, 2017).

O desenvolvimento de novas alternativas de produtos de panificação com ingredientes que substituam à farinha de trigo é algo cada vez mais desejado por consumidores, e dentre eles, os biscoitos merecem destaque devido ao seu interesse comercial, por sua aceitação, consumo e vida de prateleira. Existem também condições patológicas relacionadas à ingestão de glúten, como a doença celíaca, uma alergia alimentar, que é uma desordem autoimune, e a sensibilidade ao glúten, uma condição que surge devido à intolerância ao glúten (NASCIMENTO, 2014; LIMA et al., 2015).

Com isso, a disponibilidade de produtos sem glúten aumentou e questões relacionadas à segurança nutricional, ao sabor e ao desenvolvimento dos produtos devem ser avaliadas a fim de garantir a qualidade desses alimentos. Sendo assim, o objetivo deste trabalho foi elaborar cookies com e sem glúten, adicionados de farinha de quinoa e soja e avaliar suas características físico-químicas e sensoriais frente a uma amostra comercial de cookie com glúten.

\section{MATERIAL E MÉTODOS}

Todas as formulações foram preparadas e analisadas na Universidade Estadual do Rio Grande do Sul-UERGS, Unidade em Três Passos - RS.

\subsection{Elaboração dos cookies}




\section{Recebido em:}

$13 / 07 / 2018$

Aceito em:

$12 / 11 / 2018$

O processo de produção dos biscoitos tipo cookies com e sem glúten foi desenvolvido através de testes preliminares na cozinha experimental da universidade, baseados nos ingredientes de cookies comerciais, sendo que nas formulações desenvolvidas com e sem glúten, foram inseridas a farinha de soja e de quinoa. Na preparação dos cookies foram utilizados os seguintes utensílios: vasilhas, colheres, espátulas, formas, forno elétrico (Veit Super), batedeira (Britânia Bellagio) e embalagens plásticas. Para os testes de análise sensorial foram usados copos e pratos descartáveis.

\subsection{Ingredientes e formulações dos Cookies}

As formulações e ingredientes utilizados na elaboração dos cookies e os ingredientes das amostras de cookie comercial estão na Tabela 1.

Tabela 1 - Ingredientes usados na formulação dos cookies sem glúten (A), com glúten (B) e amostra comercial (C).

\begin{tabular}{|c|c|c|c|}
\hline Ingredientes & Cookies sem glúten (A) & $\begin{array}{l}\text { Cookies com glúten } \\
\text { (B) }\end{array}$ & $\begin{array}{l}\text { Cookies comercial } \\
\text { (C) }\end{array}$ \\
\hline Açúcar Mascavo & $125 \mathrm{~g}$ & $125 \mathrm{~g}$ & Açúcar Mascavo \\
\hline Amido de milho & $20 \mathrm{~g}$ & $20 \mathrm{~g}$ & Amido de milho \\
\hline Coco ralado & $30 \mathrm{~g}$ & $30 \mathrm{~g}$ & Coco ralado \\
\hline Farinha de quinoa & $110 \mathrm{~g}$ & $50 \mathrm{~g}$ & - \\
\hline Farinha de Soja & $20 \mathrm{~g}$ & $20 \mathrm{~g}$ & - \\
\hline Farinha de trigo & - & $45 \mathrm{~g}$ & Farinha de trigo \\
\hline Farinha de trigo int. & - & $40 \mathrm{~g}$ & Farinha de trigo int. \\
\hline Castanha-do-Pará & $85 \mathrm{~g}$ & $50 \mathrm{~g}$ & Castanha-do-pará \\
\hline Ovos & $55 \mathrm{~g}$ & $55 \mathrm{~g}$ & - \\
\hline Sal & $2 \mathrm{~g}$ & $2 \mathrm{~g}$ & Sal \\
\hline Óleo de milho & $10 \mathrm{~g}$ & $10 \mathrm{~g}$ & Óleo de milho \\
\hline Óleo de soja & $5 \mathrm{~g}$ & $5 \mathrm{~g}$ & Óleo de soja \\
\hline Canela & $0,8 \mathrm{~g}$ & $0,8 \mathrm{~g}$ & Aroma de nozes \\
\hline $\begin{array}{c}\text { Bicarbonato de } \\
\text { amônio }\end{array}$ & $2 \mathrm{~g}$ & $2 \mathrm{~g}$ & $\begin{array}{c}\text { Bicarbonato de } \\
\text { amônio }\end{array}$ \\
\hline Bicarbonato de sódio & $1 \mathrm{~g}$ & $1 \mathrm{~g}$ & Bicarbonato de sódio \\
\hline
\end{tabular}

*Farinha de trigo Int: farinha de trigo integral; farinha de trigo: farinha de trigo enriquecida com ferro e ácido fólico.

Fonte: elaborado pelo autor (2018).

A formulação dos biscoitos tipo cookies sem glúten (A) (Tabela 1) foi desenvolvida através de testes preliminares adaptadas de Correa (2010) e posteriormente para o processo de produção do biscoito realizaram-se as seguintes etapas: mistura dos ingredientes da massa em batedeira, sendo que primeiramente foram misturados: os ovos, o óleo de soja, o óleo de milho e o açúcar mascavo, por 2 minutos em velocidade média. A seguir foi acrescentada a farinha de quinoa, a farinha de soja, o amido de milho, o coco ralado, o sal, a canela, o bicarbonato de amônio e as castanhas, misturadas por $2 \mathrm{~min}$ em velocidade média. $\mathrm{O}$ forno foi pré-aquecido por 30 minutos na temperatura de $150^{\circ} \mathrm{C}$ e os cookies foram colocados em assadeiras retangulares, separados a distância de $2 \mathrm{~cm}$ um do outro, assados na temperatura de $170^{\circ} \mathrm{C}$ durante 15 minutos. Após o forneamento, os cookies foram resfriados e armazenados 
Recebido em:

$13 / 07 / 2018$

Aceito em:

$12 / 11 / 2018$

em embalagem de polietileno. O mesmo procedimento foi realizado para elaboração da formulação com glúten (B) (Tabela 1), sendo a farinha de trigo integral e a farinha de trigo branca adicionadas em substituição a farinha de quinoa e a castanha-do-Pará, cujas proporções foram reduzidas na formulação B.

A amostra comercial com glúten foi adquirida no comércio local de Três Passos. As formulações A e B (Tabela 1) foram desenvolvidas com menores quantidades de ingredientes, sendo que foram suprimidos: pirofosfato ácido de sódio, acidulante ácido cítrico, estabilizante lecitina de soja e malte de cevada.

\subsection{Análise físico-química}

As amostras foram submetidas à análise laboratorial de proteínas, lipídios, carboidratos, sódio e valor calórico segundo o Instituto Adolf Lutz (2004).

\subsection{Análise sensorial}

A avaliação sensorial dos cookies foi realizada em duas etapas. Na primeira etapa um grupo de 9 degustadores, que incluiu alunos e funcionários adultos e treinados, da UERGS Universidade Estadual do Rio Grande do Sul - Campus de Três Passos - RS, avaliou os atributos sensoriais através de metodologia descritiva quantitativa (ADQ) para aparência, sabor, textura, aroma e impressão global (DUTCOSKY, 2013). A segunda etapa consistiu em um teste afetivo de aceitabilidade com provadores não treinados, sendo 95 alunos e 5 professores do Instituto Estadual de Educação Érico Veríssimo de Três Passos - RS. Todos os participantes assinaram o termo de consentimento livre e esclarecido (TCLE, elaborado pelo equipe de pesquisa) (BRASIL, 2013) e foram excluídos os participantes que não apresentaram o termo assinado pelo responsável legal. As etapas da análise sensorial estão descritas a seguir.

Os testes sensoriais ADQ e aceitação, foram realizados individualmente, com iluminação branca, sendo que as amostras foram disponibilizadas e codificadas com três dígitos aleatórios. Juntamente com as amostras foi servida água e entregue a ficha de avaliação. As amostras foram servidas em copos descartáveis e em temperatura ambiente (DUTCOSKI, 2013).

Análise descritiva quantitativa (ADQ): A seleção dos degustadores ocorreu em duas etapas. Primeiro os interessados responderam a um questionário de avaliação de perfil, destacando-se aspectos relevantes como: vontade de participar de degustação de cookies, qual a disponibilidade de tempo, problemas de saúde (renite, diabetes, pressão alta) e gostar de cookies. Foram selecionados os participantes com o seguinte perfil: não desgostar de cookies e de biscoitos em geral, não ser fumante, não ter problemas de saúde como renite, diabete, pressão alta, ser consumidor moderado de bebida alcoólica, ou não consumidor, não ter quaisquer tipos de alergias aos cookies ou aos seus ingredientes, ter boa saúde e interesse em participar do projeto. Em seguida foi avaliada a acuidade dos degustadores em relação aos sabores, sendo aplicado um teste triangular com cookies codificados aleatoriamente sendo que os degustadores deveriam apontar qual dos cookies era diferente, pois as amostras tinham dois biscoitos iguais e um diferente.

$\mathrm{Na}$ seleção e validação da equipe de nove provadores treinados, após o treinamento, cada julgador avaliou três amostras, em triplicata, segundo os termos descritivos definidos em etapa anterior, sendo os atributos sensoriais: cor amarela, aroma de canela e castanha, sabor 


\section{Recebido em:}

$13 / 07 / 2018$

Aceito em:

$12 / 11 / 2018$

doce e de canela, e crocância. A seguir foram elaboradas fichas de avaliação com escalas não estruturadas de $9 \mathrm{~cm}$ para cada atributo, ancoradas nos pontos extremo à esquerda pelos termos "fraco", "pouco" ou "nenhum" e à direita "forte" ou "muito" para cada atributo (DUTCOSKY, 2013). Sob a supervisão do líder da equipe, os provadores discutiram o significado de cada termo e definiram de forma consensual os seis termos que melhor caracterizavam os cookies. As definições dos atributos descritivos para as amostras de cookies estão na Tabela 2.

Tabela 2 - Atributos sensoriais descritivos utilizados na análise descritiva quantitativa.

\begin{tabular}{|c|c|c|c|}
\hline \multicolumn{2}{|c|}{ Atributos Sensoriais } & \multirow[b]{2}{*}{$\begin{array}{c}\text { Definiçãa } \\
\text { Sensação produzida pela } \\
\text { estimulação da retina pelos } \\
\text { raios luminosos do } \\
\text { comprimento de onda da cor } \\
\text { amarela }\end{array}$} & \multirow[b]{2}{*}{$\begin{array}{l}\text { Referencia } \\
\text { Fraco: Leite } \\
\text { condensado } \\
\text { Forte: Bala de } \\
\text { Caramelo }\end{array}$} \\
\hline Aparência & 1 - Cor Amarela & & \\
\hline \multirow{2}{*}{ Aroma } & 2 - Castanha & $\begin{array}{c}\text { Aroma característico de } \\
\text { castanha perceptível pelo } \\
\text { órgão olfativo via retro nasal } \\
\text { durante a degustação }\end{array}$ & $\begin{array}{l}\text { Nenhum: Biscoito } \\
\text { Maria } \\
\text { Forte: Castanha }\end{array}$ \\
\hline & 3 - Canela & $\begin{array}{c}\text { Aroma característico de } \\
\text { canela, perceptível pelo } \\
\text { órgão olfativo via retro nasal } \\
\text { durante a degustação }\end{array}$ & $\begin{array}{l}\text { Nenhum: Pão } \\
\text { Muito: Chiclete de } \\
\text { canela }\end{array}$ \\
\hline \multirow[t]{2}{*}{ Sabor } & 4 - Doce & $\begin{array}{l}\text { Descreve o gosto primário } \\
\text { produzido por soluções } \\
\text { aquosas de substâncias } \\
\text { doces, semelhante à solução } \\
\text { de sacarose }\end{array}$ & $\begin{array}{c}\text { Fraco: } 0,4 \mathrm{~g} \text { de açúcar } \\
\text { em 500ml de água } \\
\text { destilada } \\
\text { Forte: Leite condensado }\end{array}$ \\
\hline & 5 - Canela & $\begin{array}{l}\text { Descreve o gosto primário } \\
\text { produzido pela presença da } \\
\text { canela no produto }\end{array}$ & $\begin{array}{c}\text { Nenhum: Pão } \\
\text { Muito: Chiclete de } \\
\text { canela }\end{array}$ \\
\hline
\end{tabular}

Fonte: Fonte: elaborado pelo autor (2018).

Os dados obtidos foram submetidos à análise estatística para seleção dos julgadores de acordo com sua habilidade em discriminar as amostras, repetibilidade e concordância com a equipe.

Análise afetiva: Nesta fase foi usado como método afetivo o teste de aceitabilidade das duas amostras desenvolvidas sem glúten (amostra A) e com glúten (amostra B). O teste foi aplicado para 100 alunos e professores, sem restrição quanto ao sexo, idade e frequência de consumo.

Os avaliadores receberam uma porção de cada amostra (aproximadamente $10 \mathrm{~g}$ ), em pratos plásticos descartáveis brancos, codificados com números de três dígitos, de forma aleatória e balanceada, acompanhados de um copo de água para realização do branco. As formulações foram oferecidas aos avaliadores de forma monódica sequencial. 


\section{Recebido em:}

$13 / 07 / 2018$

Aceito em:

$12 / 11 / 2018$

As amostras foram avaliadas quanto à aceitabilidade geral do produto e em particular quanto a aparência, aroma, sabor, textura e impressão global, por meio de escalas hedônicas de nove pontos $(9=$ gostei extremamente, $5=$ não gostei nem desgostei e $1=$ desgostei extremamente). Os dados relativos às escalas utilizadas foram submetidos à análise de variância e teste de Tukey para comparação de médias, foi utilizado o programa estatístico Statistical Analytical Systems - SAS Use's Guide: Version 6.11 (SAS, 1996).

\section{RESULTADOS E DISCUSSÃO}

\subsection{Caracterização físico-química dos biscoitos tipo cookies} Tabela 3.

Os resultados das análises físico-químicas dos cookies sem e com glúten estão na

Tabela 3 - Caracterização físico-química dos cookies sem glúten (A), cookies com glúten (B) e cookie comercial (C).

\begin{tabular}{cccc}
\hline Análises & $\begin{array}{c}\text { Cookies sem glúten } \\
(\mathbf{A})\end{array}$ & $\begin{array}{c}\text { Cookies com glúten } \\
(\mathbf{B})\end{array}$ & $\begin{array}{c}\text { Cookie comercial } \\
(\mathbf{C})\end{array}$ \\
\hline Proteína bruta $(\%)$ & $10,83 \pm 0,31$ & $11,53 \pm 0,29$ & 8,00 \\
Gordura total (\%) & $10,36 \pm 0,19$ & $10,80 \pm 0,16$ & 13,00 \\
Carboidratos $(\%)$ & $38,42 \pm 0,12$ & $43,88 \pm 0,09$ & 66,00 \\
Sódio (mg/100g) & $182,73 \pm 0,25$ & $177,30 \pm 0,17$ & 133,33 \\
Valor calórico (Kcal) & $290,33 \pm 0,11$ & $318,66 \pm 0,05$ & 423,33 \\
\hline
\end{tabular}

*Valores expressos como Média \pm Desvio-padrão.

Fonte: elaborado pelo autor (2018).

Conforme os resultados da Tabela 3, é possível verificar que o teor de proteína bruta variou de $10,83 \%$ a $11,53 \%$ para as amostras A e B, indicando que a amostra B apresenta maior teor nutricional quando comparado com A. Ao comparar estes teores com a amostra comercial, verificou-se valores de proteína maiores, pois a amostra referência apresenta valor de proteína $8 \%$. Este maior teor proteico dos cookies produzidos, provavelmente ocorre devido a adição de soja e quinoa, que apresentam elevados teores médios de proteína de $36 \%$ (LIU; KUO, 2016) e 15\% (NAVRUZ-VARLI; SANLIER, 2016), respectivamente. Para a gordura total obteve-se os teores de 10,36 e 10,80\% para as amostras A e B, respectivamente, valores estes, menores do que o verificado na amostra referência que apresentou $13 \%$. A adição destes ingredientes pode favorecer a obtenção de um produto com valor nutricional agregado.

Mariani et al. (2015) concluíram que os biscoitos elaborados com farelo de arroz e farinha de soja apresentaram características promissoras em relação ao teor proteico e às cinzas. No estudo de Freitas et al. (2014), foi verificado que ao adicionar farinhas de sementes de abóbora e bauru em formulações de biscoitos para celíacos, houve melhora no conteúdo nutricional em relação aos teores de proteínas e lipídios.

\subsection{Avaliação do desempenho da equipe para ADQ e seleção de provadores}




\section{Recebido em:}

$13 / 07 / 2018$

Aceito em:

$12 / 11 / 2018$

Os valores médios obtidos para cada atributo de avaliação das amostras pela equipe treinada inicialmente composta por 9 julgadores encontram-se na Tabela 4.

Tabela 4 - Valores médios obtidos na avaliação em triplicata das amostras por 9 julgadores treinados para análise descritiva quantitativa visando a validação da equipe.

\begin{tabular}{cccccc}
\hline \multicolumn{2}{c}{ Atributos Sensoriais } & $(\mathbf{A})$ & $\mathbf{( B )}$ & $\mathbf{( C )}$ & d.m.s. $(5 \%)$ \\
\hline Aparência & Cor Amarela & $3,2 \pm 1,7^{\mathrm{c}}$ & $4,3 \pm 2,2^{\mathrm{b}}$ & $6,7 \pm 2,0^{\mathrm{a}}$ & 0,88 \\
Aroma & Castanha & $3,4 \pm 2,3^{\mathrm{a}}$ & $1,8 \pm 2,4^{\mathrm{b}}$ & $3,0 \pm 2,5^{\mathrm{a}}$ & 1,17 \\
& Canela & $3,6 \pm 2,4^{\mathrm{a}}$ & $1,2 \pm 1,5^{\mathrm{b}}$ & $2,2 \pm 2,7^{\mathrm{b}}$ & 0,96 \\
Sabor & Doce & $4,7 \pm 1,8^{\mathrm{a}}$ & $2,8 \pm 1,3^{\mathrm{b}}$ & $4,0 \pm 2,0^{\mathrm{a}}$ & 0,91 \\
& Canela & $3,2 \pm 2,1^{\mathrm{a}}$ & $0,9 \pm 0,8^{\mathrm{c}}$ & $1,7 \pm 2,4^{\mathrm{b}}$ & 0,64 \\
Crocância & & $3,2 \pm 1,9^{\mathrm{a}}$ & $1,0 \pm 0,7^{\mathrm{c}}$ & $7,3 \pm 1,3^{\mathrm{b}}$ & 0,69 \\
\hline
\end{tabular}

*Valores expressos como Média \pm Desvio-padrão entre os 9 julgadores treinados. D.M.S.: diferença mínima significativa ao nível de $95 \%$ de confiança (Teste de Tukey). Para cada atributo, valores seguidos de letras iguais não diferem estatisticamente entre si ao nível de erro de $5 \%$.

Fonte: elaborado pelo autor (2018).

Conforme a Tabela 4, é possível verificar que a equipe foi capaz de detectar diferenças significativas entre a maior parte das amostras para os 6 atributos avaliados, o que representa um desempenho muito bom da equipe como um todo, embora os valores de desvio padrão relativos às médias obtidas para algumas amostras e atributos sejam relativamente elevados, o que indica que os julgadores utilizaram partes distintas das escalas. Os valores da estatística $\mathrm{F}$ para a interação amostra versus provador não foram significativos ao nível de erro de $5 \%$ em todos os atributos avaliados, isto indica que não houve influência significativa das avaliações diferenciadas entre os provadores.

O resultado da análise dos dados individuais de cada julgador para cada atributo isolando os fatores repetições e amostras é apresentado na Tabela 5, que mostra que a maioria dos julgadores foi capaz de discriminar as amostras na maioria dos atributos. Somente o provador 4 apresentou um menor número de atributos discriminados (4 atributos). Nenhum provador apresentou falta de repetibilidade. A Tabela 5 apresenta os dados da avaliação da Análise Descritiva Quantitativa (ADQ) e pode-se observar que a cor amarela, o sabor de canela e a crocância distinguiu as três amostras entre $\mathrm{si}(\mathrm{p} \leq 0,05)$. 
Tabela 5 - Níveis de significância (p) para provadores em função da discriminação das amostras (p amostra) e da repetibilidade ( $\mathrm{p}$ repetição).

\begin{tabular}{|c|c|c|c|c|c|c|c|c|c|c|}
\hline \multirow{2}{*}{\multicolumn{2}{|c|}{ Atributos Sensoriais }} & \multicolumn{9}{|c|}{ Provadores } \\
\hline & & 1 & 2 & 3 & 4 & 5 & 6 & 7 & 8 & 9 \\
\hline \multirow{2}{*}{ Cor Amarela } & $p_{\text {amostra }}$ & 0,0190 & 0,1172 & $0,8133 *$ & 0,0413 & 0,0034 & 0,0055 & 0,0705 & 0,0643 & 0,0092 \\
\hline & $p$ repetição & 0,5555 & 0,3169 & 0,5396 & 0,4438 & 0,2559 & 0,2812 & 0,6798 & 0,6241 & 0,3831 \\
\hline \multirow{2}{*}{$\begin{array}{l}\text { Aroma } \\
\text { Castanha }\end{array}$} & $p$ amostra & $0,5204 *$ & 0,0283 & 0,0051 & 0,2544 & 0,1482 & 0,1593 & 0,2889 & 0,0542 & 0,2000 \\
\hline & $p$ repetição & 0,2997 & 0,3092 & 0,8211 & 0,2831 & 0,3249 & 0,9225 & 0,5531 & 0,3212 & 0,1075 \\
\hline \multirow{2}{*}{ Aroma Canela } & $p$ amostra & 0,0079 & 0,0185 & 0,0125 & $0,9152 *$ & 0,0600 & 0,0268 & 0,1119 & 0,0713 & 0,1255 \\
\hline & $p$ repetição & 0,0715 & 0,3875 & 0,8119 & 0,7385 & 0,4467 & 0,2745 & 0,8622 & 0,3065 & 0,1710 \\
\hline \multirow{2}{*}{ Sabor Doce } & $p_{\text {amostra }}$ & 0,1545 & 0,0022 & 0,3383 & $0,9527 *$ & 0,2223 & $0,7338 *$ & 0,0284 & 0,0690 & 0,0386 \\
\hline & $p$ repetição & 0,8103 & 0,1867 & 0,1314 & 0,7416 & 0,3285 & 0,8203 & 0,3918 & 0,3821 & 0,2390 \\
\hline \multirow{2}{*}{ Sabor Canela } & $p$ amostra & 0,0505 & 0,0083 & 0,0047 & 0,0367 & 0,0174 & 0,0208 & 0,2478 & $0,5419 *$ & 0,0007 \\
\hline & $p$ repetição & 0,6489 & 0,4969 & 0,6284 & 0,0815 & 0,2879 & 0,5903 & 0,5051 & 0,7329 & 0,2520 \\
\hline \multirow{2}{*}{ Crocância } & $p$ amostra & 0,0001 & 0,0074 & 0,0009 & 0,0003 & 0,0149 & 0,0004 & 0,0009 & 0,0344 & 0,0003 \\
\hline & $p$ repetição & 0,1934 & 0,9129 & 0,6977 & 0,0845 & 0,2696 & 0,6689 & 0,0991 & 0,2247 & 0,5970 \\
\hline \multicolumn{2}{|c|}{ Discriminância amostras $(\mathrm{p}<0,50)$} & 5 & 6 & 5 & 4 & 6 & 5 & 6 & 5 & 6 \\
\hline \multicolumn{2}{|c|}{ Falta de repetibilidade $(\mathrm{p}<0,05)$} & 0 & 0 & 0 & 0 & 0 & 0 & 0 & 0 & 0 \\
\hline
\end{tabular}


Recebido em:

$13 / 07 / 2018$

Aceito em:

$12 / 11 / 2018$

A amostra $\mathrm{C}$ foi considerada com intensidade de cor amarela forte, a amostra $\mathrm{A}$ com intensidade de cor fraca e a amostra $\mathrm{B}$ com intensidade de cor intermediária. O sabor de canela foi considerado fraco para a amostra A, muito fraco para a amostra B e com média intermediária, entre fraco e muito fraco, para a amostra $\mathrm{C}$. A amostra $\mathrm{C}$ foi considerada muito crocante, a amostra A apresentou pouca crocância e a amostra B muito pouca crocância.

$\mathrm{O}$ aroma de canela foi considerado entre fraco e moderado para a amostra A que foi mais intenso $(p \leq 0,05)$ do que as amostras $B$ e $C$, as quais obtiveram médias entre muito fraco e fraco e não foram significativamente diferentes entre si. As médias obtidas na avaliação do atributo castanha para as amostras A e C correspondem a fraco na escala utilizada, não diferiram entre si, e este atributo foi considerado mais intenso $(\mathrm{p} \leq 0,05)$ nestas duas amostras do que na amostra B, com média entre muito fraco e fraco. A amostra A obteve média próxima à sabor doce moderado e a amostra $\mathrm{C}$ entre fraco e moderado, estas duas amostras não diferiram entre si e foram consideradas mais doces $(\mathrm{p} \leq 0,05)$ do que a amostra $\mathrm{B}$ com média próxima ao que corresponde a fraco (Tabela 5).

\subsection{Teste de aceitabilidade}

Os resultados de média do desvio padrão dos 100 julgadores, obtidos no teste de aceitabilidade do produto de modo global, e em particular quanto à aparência, ao aroma, ao sabor e à textura são apresentados na Tabela 6, de acordo com a escala atribuída.

Tabela 6 - Resultados obtidos no teste para avaliação da aceitabilidade do produto quanto à aparência, aroma, sabor, textura e a impressão de modo global das amostras *.

\begin{tabular}{cccccc}
\hline Amostras & Aparência & Aroma & Sabor & Textura & Imp. global \\
\hline Amostra A & $7,1^{\mathrm{a}}$ & $7,4^{\mathrm{a}}$ & $7,9^{\mathrm{a}}$ & $7,2^{\mathrm{a}}$ & $7,4^{\mathrm{a}}$ \\
Amostra B & $7,0^{\mathrm{a}}$ & $7,3^{\mathrm{a}}$ & $7,1^{\mathrm{b}}$ & $7,4^{\mathrm{a}}$ & $7,2^{\mathrm{a}}$ \\
\hline
\end{tabular}

*Valores seguidos de letras iguais não diferem estatisticamente entre si ao nível de erro de 5\%.

Fonte: elaborado pelo autor (2018).

Quanto à aceitabilidade, verifica-se que as amostras obtiveram médias ligeiramente superiores a "gostei moderadamente" na escala utilizada e não diferiram estatisticamente entre si ao nível de erro de $5 \%(\mathrm{p}<0,05)$ para todos os atributos avaliados, exceto para o sabor. A amostra A sem glúten obteve média correspondente a "gostei muito" quanto ao sabor, sendo mais aceita $(\mathrm{p}<0,05)$ do que a amostra $\mathrm{B}$ com glúten, com média próxima ao que corresponde à "gostei moderadamente". A Figura 1 apresenta a distribuição em frequência pelos consumidores das Amostras A (a) e Amostra B (b), quanto as amostras de aceitabilidade da aparência, aroma, sabor, textura e modo geral.

Figura 1 - Distribuição em frequência pelos consumidores quanto a aceitabilidade das amostras quanto a aparência, aroma, sabor, textura e impressão de modo global. 
Recebido em:

$13 / 07 / 2018$

Aceito em:

$12 / 11 / 2018$

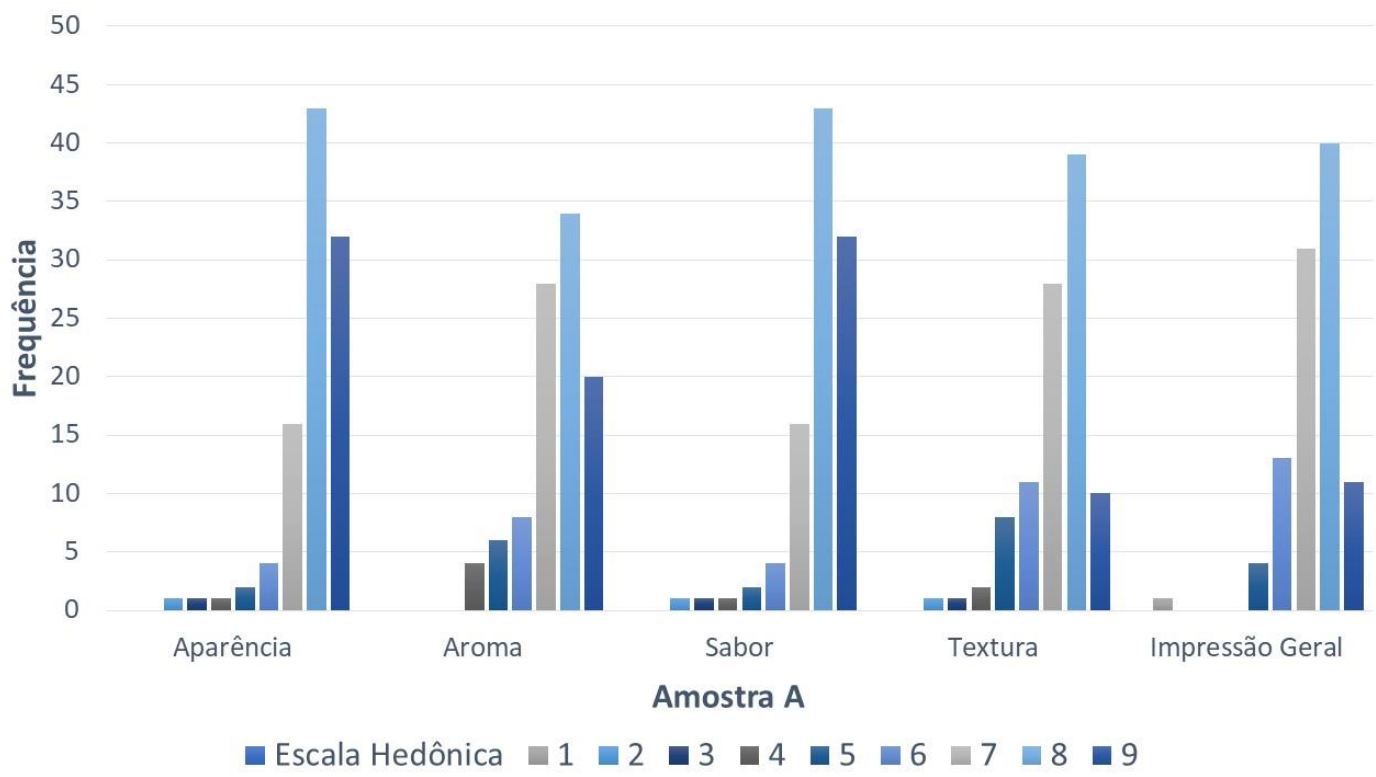

(a)

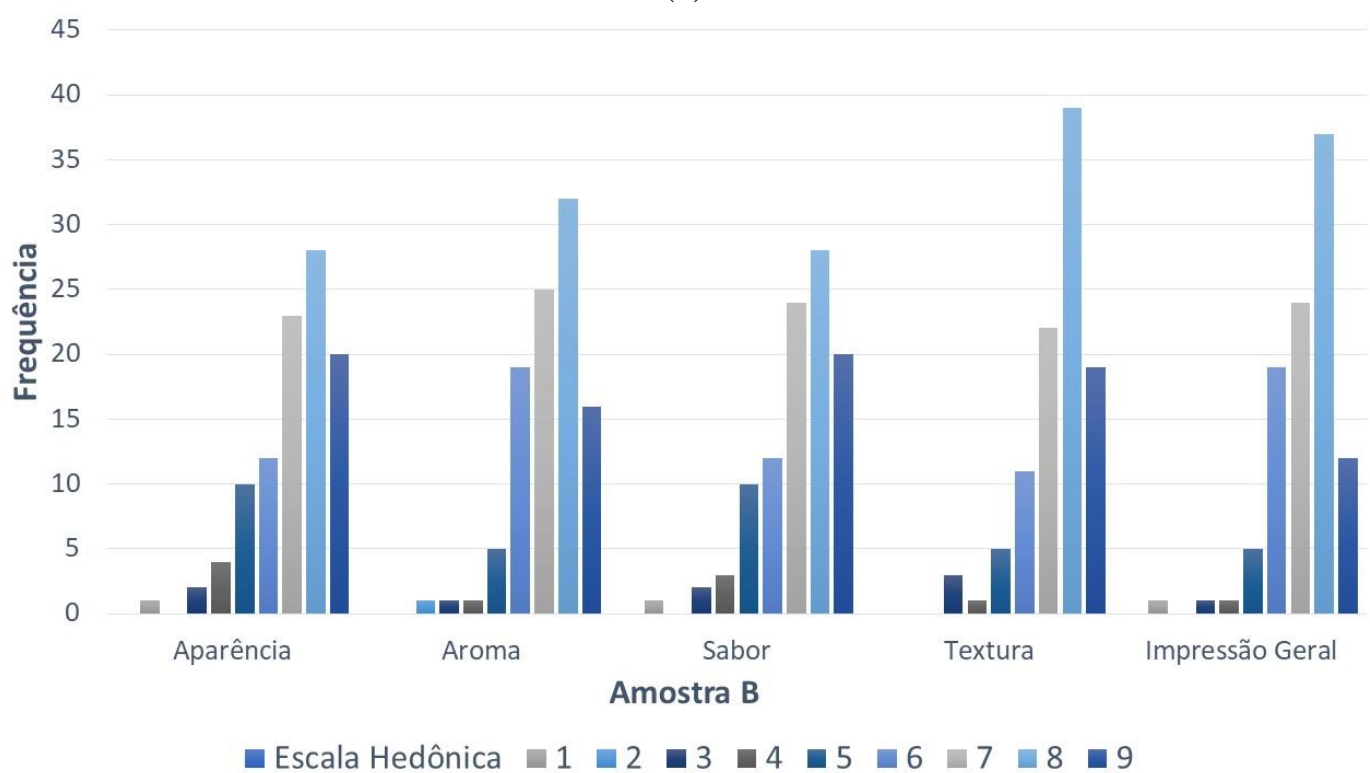

(b)

Fonte: elaborado pelo autor (2018).

Um dos empecilhos para a produção de panificados sem farinha de trigo é a condição sensorial dos produtos isentos de glúten, porém é possível verificar que as características de aceitação do biscoito contendo glúten e do que não contém glúten foram similares, mas diferentes para o sabor, o que pode ter ocorrido pela adição de farinha de trigo no cookie com glúten (amostra B). SOARES JR et al. (2009) verificaram redução nos escores médios relacionados ao atributo textura em pães à medida que a farinha de trigo foi substituída por farelo de arroz torrado e, atribuíram como uma das causas dessa redução, as características 
Recebido em:

$13 / 07 / 2018$

Aceito em:

$12 / 11 / 2018$

tecnológicas das fibras e seus efeitos sobre outros componentes do alimento. Destacam ainda a necessidade de adequar um maior nível de fibra com a menor mudança possível nas características sensoriais, principalmente a textura de alimentos alternativos, tornando o produto aceitável pelo consumidor.

Os teores de proteína e fibras, para os dois tipos de cookies desenvolvidos, foram maiores que os verificados para amostras comerciais deste tipo de produto, demostrando que é de grande importância a formulação de biscoitos tipo cookie contendo soja e quinoa, pois além de conterem maiores níveis de proteínas e fibras apresentaram boa aceitação entre os potenciais consumidores. Em estudo realizado em 2014 com cookies sem glúten contendo farinha de quinoa (Linum usitatissimum), comprovou-se ser um produto com sabor diferenciado e de boa aceitabilidade em relação aos atributos sensoriais avaliados (PAGAMUNICI et al., 2014). A farinha de soja é amplamente utilizada na indústria como um ingrediente para aumentar o conteúdo proteico de produtos de panificação, e também apresenta boa aceitabilidade sensorial (CAVALHEIRO et al., 2001; MARETI et al., 2010; MARIANI et al., 2015).

\section{CONCLUSÃO}

Os biscoitos tipo cookie desenvolvidos com e outro sem glúten, adicionados de soja e quinoa, ingredientes com alto valor nutricional em termos de proteínas e fibras, apresentam-se como uma alternativa de alimentos isentos de glúten destinados para indivíduos portadores de doença celíaca. Além disso, para quem procura produtos diferenciados e saudáveis no mercado, pois apresentaram características sensoriais de aceitabilidade pelo consumidor, médias ligeiramente superiores a "gostei moderadamente" na escala utilizada e não diferiram estatisticamente entre si ao nível de erro de $5 \%(\mathrm{p}<0,05)$ para todos os atributos avaliados, exceto para o sabor. O cookie sem glúten obteve média correspondente a "gostei muito" quanto ao sabor, sendo mais aceito $(\mathrm{p}<0,05)$ do que o cookie com glúten, com média próxima ao que corresponde à "gostei moderadamente".

Os resultados da ADQ demonstraram que o cookie sem glúten foi caracterizado como de cor amarela e sabor de canela fraco, com pouca crocância. $O$ aroma de canela foi considerado entre fraco e moderado, mas ainda mais intenso do que para o cookie com glúten. O sabor doce foi considerado moderado, mas ainda superior (mais doce) do que o cookie com glúten. O cookie com glúten apresentou cor amarela intermediária, sabor de canela muito fraco e pouca crocância.

\section{AGRADECIMENTOS}

Agradecemos à FAPERGS pelo auxílio financeiro ao projeto.

\section{REFERÊNCIAS BIBLIOGRÁFICAS}


Recebido em:

$13 / 07 / 2018$

Aceito em:

$12 / 11 / 2018$

ABIMAPI, Associação Brasileira das Indústrias de Biscoitos, Massas. Disponível em http://www.investimentosenoticias.com.br/noticias/negocios/abimapi-registra-crescimentode-50-das-exportacoes-em-2017. Acesso em outubro de 2018.

ARAÚJO, H. M. C. et al. Doença celíaca, hábitos e práticas alimentares e qualidade de vida. Revista de Nutrição, Campinas, v. 23, n. 3, p. 467-474, maio/jun. 2010.

BRASIL. Agência Nacional de Vigilância Sanitária - ANVISA. Resolução - RDC nº 263, de 22 de setembro de 2005. Diário Oficial [da] República Federativa do Brasil, Brasilia, DF, 23 set. 2005.

BRASIL. Ministério da Saúde. Conselho Nacional de Saúde. Resolução no 466, de 12 de dezembro de 2012. Diário Oficial [da] República Federativa do Brasil, Brasília, DF, 13 jun. 2013.

CARRÃO-PANIZZI, M. C.; SILVA, J. B. Soja na alimentação humana: qualidade na produção de grãos com valor agregado. Congresso de La Soja Del Mercosur - Mercosoja, $5^{\circ}$ Edição, Rosário, p. 1-3, 2011.

CAVALHEIRO, S. F. L. et al. Biscoito sabor chocolate com resíduo de soja," okara": teste afetivo com crianças em idade pré-escolar. Alimentos e Nutrição Araraquara, São Paulo, v. 12, n. 1, p. 151-162, jul. 2001.

CORREA, M. M. Receitas toques e truques. 1. ed. São Paulo: RPB, 2010.

CORTAT, C. M. et al. Desenvolvimento de biscoito tipo cookie isento de glúten à base de farinha de banana verde e óleo de coco. Revista Hospital Universitário Pedro Ernesto, Rio de Janeiro, v. 14, n. 3, p. 20-26, jul/set. 2015.

DA SILVA, B. A. et al. Elaboração de Biscoitos a Partir da Biomassa da Banana Verde. CIENTEC, Recife, v. 9, n. 1, p. 136-140, set. 2017.

DEVI, K.; HARIPRIYA, S. Pasting behaviors of starch and protein in soy flour- enriched composite flours on quality of biscuits. Journal of food Processing and Preservation, Puducherry, v. 38, n. 1, p. 116-124, fev. 2014.

GOES, E. S. R. et al. Elaboração de biscoitos tipo "cookies" com inclusão de peixe. Revista Agrarian, Dourados, v. 10, n. 37, p. 245-253, mai. 2017.

DOS SANTOS, A. T. et al. Análise sensorial de um biscoito funcional a base de cacau e aveia. Revista Intertox de Toxicologia, Risco Ambiental e Sociedade, São Paulo, v. 8, n. 3, p. 79-89, out. 2015 .

DUTCOSKY, S. D. Análise sensorial de alimentos. 4. ed. Curitiba: Champagnat, 2013. 
Recebido em:

13/07/2018

Aceito em:

12/11/2018

FIORAVANTE, M. B. et al. Qualidade nutricional e funcional de biscoito de farinha de caraguatá (Bromelia Balansae Mez). Revista Uniabeu, Belford Roxo, v. 9, n. 22, p. 221-235, maio/ago. 2016.

FREITAS, C. J.; VALENTE, D. R. E.; CRUZ, S. P. Caracterização física, química e sensorial de biscoitos confeccionados com farinha de semente de abóbora (FSA) e farinha de semente de baru (FSB) para celíacos. Demetra: alimentação, nutrição e saúde, Rio de Janeiro, v. 9, n. 4, p. 1003-1018, 2014.

GEWEHR, M. F. et al. Análises químicas em flocos de quinoa: caracterização para uso em produtos alimentícios. Brazilian Journal Food Technology, Campinas, v. 15, n. 4, p. 280287, out/dez. 2012.

LIMA, J. P. et al. Farinha de entrecasca de melancia em biscoitos sem glúten. Ciência Rural, Santa Maria, v. 45, n. 9, p. 1688-1694, set. 2015.

LIU, H.-H.; KUO, M.-I. Ultra high pressure homogenization effect on the proteins in soy flour. Food Hydrocolloids, v. 52, p. 741-748, 2016.

LOPES, A. C. Mucilagem de chia e sua utilização no processamento de biscoito salgado isento de glúten. 2017. 73 f. Dissertação (Mestrado Profissional em Tecnologia de Alimentos) - Universidade Tecnológica Federal do Paraná, Programa de Pós Graduação em Tecnologia de Alimentos, Londrina, 2017.

MAKINO, A. V.; OTOBONI, A. M. M. B. Biscoitos do tipo cookie "kekse" desenvolvidos à base de batata-doce. Revista Raízes e Amidos Tropicais, Botucatu, v. 13, n. 1, p. 73-89, 2018.

MARETI, M. C.; GROSSMANN, M. V. E.; BENASSI, M. D. T. Características físicas e sensoriais de biscoitos com farinha de soja e farelo de aveia. Ciência e Tecnologia de Alimentos, Campinas, v. 30, n. 4, p. 878-883, out/dez. 2010.

MARIANI, M. et al. Elaboração e avaliação de biscoitos sem glúten a partir de farelo de arroz e farinhas de arroz e de soja. Brazilian Journal of Food Technology, Campinas, v. 18, n. 1, p. $70-78$, jan/mar. 2015.

MORAES, K. S. et al. Avaliação tecnológica de biscoitos tipo cookie com variações nos teores de lipídio e de açúcar. Ciência e Tecnologia de Alimentos, Campinas, v. 30, p. 233242, maio. 2010.

NASCIMENTO, A. B. D. Desenvolvimento de produto alimentício sem glúten elaborado a partir da percepção de consumidores celíacos. 2014. 181 f. Tese (Doutorado em Ciências dos Alimentos) - Universidade Federal de Santa Catarina UFSC, Programa de Pós-graduação em Ciências dos Alimentos, Florianópolis, 2014. 
Recebido em:

$13 / 07 / 2018$

Aceito em:

$12 / 11 / 2018$

NAVRUZ-VARLI A.; SANLIER, B. Nutritional and health benefits of quinoa (Chenopodium quinoa Willd.). Journal of Cereal Science, Besevler, v. 69, p. 371-376, maio. 2016.

OLIVEIRA, D. I. et al. Biscoitos tipo cookie sem glúten formulados com farelo de feijão, farinha de arroz e amido de mandioca. Revista Brasileira de Tecnologia Agroindustrial, Ponta Grossa, v. 11, n. 2, p. 2502-2522, jul/dez. 2017.

PAGAMUNICI, M. P. et al. Using chemometric techniques to characterize gluten-free cookies containing the whole flour of a new quinoa cultivar. Journal of the Brazilian Chemical Society, São Paulo, v. 25, n. 2, p. 219-228, fev. 2014.

PEREIRA, A. P. A. Efeito da adição de amoras-pretas (Rubus sp) em cookies de grãos inteiros: avaliação das propriedades funcionais, tecnológicas e sensoriais. 2016. $92 \mathrm{f}$. Dissertação (Mestrado em Ciência de Alimentos) - Universidade Estadual de Campinas, Faculdade de Engenharia de Engenharia de Alimentos, Campinas, 2016.

RIGO, M. Avaliação físico-química e sensorial de biscoitos tipo cookie adicionados de farinha de bagaço de malte como fonte de fibra. Ambiência, Guarapuava, v. 13, n. 1, p. 4757, jan/abr. 2017

SABINO, V. G. et al. Desenvolvimento e caracterização de biscoitos tipo cookie de farinha do resíduo agroindustrial do caju. Revista Brasileira de Agrotecnologia, Garanhuns, v. 7, n. 2, p. 38-44, 2017.

STATYSTICAL ANALISYS SISTEM - SAS. SAS/STAT: user's guide. 11th ed. Cary: Sas Institute Inc., 1996. Version 6.

SILVA, M. R.; SILVA, M. A. A. P.; CHANG, Y. K. Utilização da farinha de jatobá (Hymenaeastigonocarpa Mart.) na elaboração de biscoitos tipo cookie e avaliação de aceitação por testes sensoriais afetivos univariados e multivariados. Ciência e Tecnologia de Alimentos, v. 18, n. 1, p. 25-34, 1998.

SOARES JÚNIOR, M. et al. Qualidade de biscoitos formulados com diferentes teores de farinha de casca de pequi. Pesquisa Agropecuária Tropical, Goiânia, v. 39, n. 2, p. 98-104, abr/jun. 2009.

TEKGÜLER, B.; ILKAY, K. O. C. A.; KITAN, S. Quinoa (chenopodium quinoa willd.) As functional foods. Comprehensive Reviews in Food Science and Food Safety, v. 14, p. 431445, fev. 2015.

VIEIRA et al. Efeito da substituição da farinha de trigo no desenvolvimento de biscoitos sem glúten. Brazilian Jornal and Food Technology, Campinas, v. 18, n. 4, p. 285-292, out./dez. 2015. 
Revista CSBEA - v. 4, n. 1 (2018) 80

Recebido em:

$13 / 07 / 2018$

Aceito em:

$12 / 11 / 2018$

VILCACUNDO, R.; HERNÁNDEZ-LEDESMA, B. Nutritional and biological value of quinoa (Chenopodium quinoa Willd.). Current Opinion in Food Science, v. 14, p. 1-6, abr. 2017. 